\title{
Influence of Five-Elements Theory, Myths And Legends Acting On Character Structure of the Legend of the Condor Heroes
}

\author{
Qian Ma \\ School of Management Science and Engineering \\ Zhengzhou University of Aeronautics \\ Zhengzhou, China \\ E-mail: 251047276@qq.com
}

\begin{abstract}
Exploration and study of contemporary scholars and martial arts enthusiasts of Jin Yong's novels has never stopped, Jin studies already became a famous doctrine. From macro to micro, the research methods include the study of history, sociology, customs, religion and so on. Based on the text, using microscopic methods, the main characters spectrum of the legend of the Condor Heroes was found out. Three respective comparisons were made between the main characters spectrum and three kinds of literature materials including the ancient Five-Elements theory, myths and legends. In order to find the association and the inheritance, to explore the prototype and create context of the main characters of the Legend of the Condor Heroes. And to concise out classical literary elements in the Legend of the Condor Heroes.
\end{abstract}

Keywords-the Legend of the Condor Heroes; Five-Elements theory; Myths and legends; text research

\section{INTRODUCTION}

Jin Yong's novels presented the broad historical background and the mainstream ideology which were always praiseworthy, however, the reason which attracts generations of readers eager to read is not only limited in this area. People who focus on the history, can read the history books, probes into thought and theories, can also go to read the Analects of Confucius and the Daodejing. But why is it that many Chinese people are fond of Jin Yong's novels? That is because he couched in popular language to convey the Chinese classical emotions appropriately fit the Chinese cultural background, so that readers can have a strong sense of identity. In this paper, use Legend of the Condor Heroes as an example, based on the text, to analyze its inheritance of the ancient Five-Ele ments theory using the relationship of the characters in the architecture as the breakthrough point. To explore its absorbability and inheritance of the Chinese classical literature using the characterization as the breakthrough point.

\section{RELATIONSHIP BETWEENTHE CHARACTER STRUCTURES AND THE FIVE-ELEMENT S THEORY}

The character structures of the legend of the Condor Heroes are stable and elegant, which inherited the ancient thought of the Five-Elements theory.

In all of Jin Yong's novels, the oldest background which was based on is the Legend of the condor Heroes. Its character pedigree created subsequent architecture of other novels of Jin Yong. Although Mr Jin Yong once said, When I wrote the first novel, I didn't know whether to write the second novel. When I wrote the second novel, I had no thought of the novel theme. But the readers who had read all of Jin Yong's works should understand that characters in each of his novels are inherited, neither a whim, nor a random creation. The source of the character structures is just in the legend of the Condor Heroes.

The Five-Elements theory experts whose theory was based on ancient creation myths and primitive totem worship, give five directions, north and south, east and west with the corresponding colors, patron saint and holy beast which according to the theory of YIN, YANG and five elements. With such a stable structure, they constructed the ancient Chinese people's world outlook and cognitive basis, which were quickly recognized and inherited. Because the ancient Chinese myths and legends was not a system, in fact there were many sources. The details of the Five-Elements theory were no unified. A kind of view is that the Fivecolors dragons reflected the thoughts of the Five-Elements theory. The other kind of view is that the Five-Elements theory was mirrored by the yellow dragon and the four holy beasts, however that arguments about four holy beast were not unified, this paper just choose one of them.

In the legend of the Condor Heroes, Jin Yong portrayed the image of a number of famous martial artist, that was known as the "five greats" whose martial arts in the world were really the most superior. No matter the name of the character given, or the shaping of the novel characters, there were lots of signs of the Five-Ele ments theory. 
TABLE1. The structure of the five elements theory

\begin{tabular}{|l|l|l|l|l|}
\hline $\begin{array}{c}\text { Orientat } \\
\text { ion }\end{array}$ & $\begin{array}{c}\text { Matching } \\
\text { color }\end{array}$ & $\begin{array}{c}\text { Matching } \\
\text { element }\end{array}$ & \multicolumn{1}{|c|}{ Holy beast } & \multicolumn{1}{|c|}{$\begin{array}{c}\text { Patron } \\
\text { saint }\end{array}$} \\
\hline east & cyan & wood & $\begin{array}{l}\text { the cyan } \\
\text { dragon }\end{array}$ & Gou Mang \\
\hline west & white & gold & the white tiger & Ru Shou \\
\hline south & vermilion & fire & the rosefinch & Zhu Rong \\
\hline north & black & water & $\begin{array}{l}\text { the tortoise } \\
\text { snake form- } \\
\text { fitting beast }\end{array}$ & Gong Gong \\
\hline centre & yellow & soil & $\begin{array}{l}\text { the yellow } \\
\text { dragon }\end{array}$ & Hou Tu \\
\hline
\end{tabular}

The "five greats" who came from The legend of the Condor Heroes, were great masters of martial arts that whose nicknames were eastern weirdo, western evils, southern emperor, northern beggar, coupled with the central avatar.

Huang Yaoshi, nicknamed the eastern weirdo, liked cyan long gown, living on Taohua Island in the east China sea, where the island was full of peach trees. Because oriental matched the wood, those three Chinese characters Huang, Yao, Tao which came from the name and residence, some had grass character attributes and some had wood character attributes. And novel set the plot that the eastern weirdo lived around the peach trees. The spring god Gou Mang was in charge of the oriental, was also a pharmacist who was good at refining medicine. So the eastern weirdo was named pharmacist in this novel, and was endowed with an ability which was similar to a pharmacist. According to the theory, generation among five elements referred to the relationship in which each element promoted another sequential one. Specifically, water could promote wood. So this novel set the plot that the Taohua Island was located in the east China sea. Oriental matched the cyan, so the eastern weirdo was always dressed in a piece of cyan long gown. Oriental matched the cyan dragon as the holy beast which has the most versatile character and noble wisdom. Therefore, the eastern weirdo was endowed with the character of rebelling against orthodoxy, lofty a loof, high intelligence quotient. In order to highlight his character, he was nicknamed with " weirdo " .

Ouyang Feng, nicknamed the western evils, always wore a piece of white robe, was a blond western people. He lived in the White Camel Mountain in western regions of China. He was good at raising snakes and using poison. Because the west matched the metal, novel named him with a Chinese character Feng and endowed him with "eyes such as electricity, the look in the eyes such as knife and sword, which was very sharp," also endowed him with the voice sounded like the sound of metal. The god of war Ru Shou was in charge of the west, and was with a snake in his ear. So novel set the plot that the west evils was good at raising snakes and using poison, using the caduceus as his weapon. According to the theory, generation among five elements referred to the the relationship in which each element restricted another sequential one. Specifically, fire could restrict metal. So novel set the plot that the trick of western evils had once been defeated by a kind of Qigong trick called Yiyangzhi. The creator of Yiyangzhi was just the southern emperor who matched to the fire according to the Five-Elements theory. West matched white, so the western evils was always dressed in a piece of white robe and lived in the White Camel Mountain. West matched the white tiger as the holy beast which was very formidable. So, the western evils was endowed with the character of malevolence and cunning. In order to highlight his character, he was nicknamed with " evils ".

Master Monk Yi Deng, whose real name was Duan Zhixing, nicknamed southern emperor or southern monks, formerly lived at Yunnan, Dali. After abdicateing, he became a monk who was always dressed in a piece of vermilion cassock. Because the south matched the fire, those two Chinese characters Deng, Xing were related to the fire. Deng had fire character attributes according to the Chinese characters word-formation. The Chinese-traditional character of Xing which was an associative compound had the fire character attributes in it. In former times, Suiren invented drilling wood to make fire, but was unable to save the fire. The patron saint Zhu Rong who was in charge of the south, created the methods of using and keeping fire on the basis of Suiren. In novel, Master Monk Yi Deng was endowed with a kind of Qigong trick called Yiyangzhi, which was able to blow out the candles in a far distance, of course was able to defeat the enemies by the invisible power. According to the Five-Elements theory,fire could promote soil, meanwhile fire could restrict metal. So, the southern emperor who matched to the fire taught Yiyangzhi to the central avatar who matched to the soil. Afterwards, the central avatar defeated the western evils who matched to the soil. The novel mentioned several times that the southern emperor's Yiyangzhi was just the buster of the western evils' toad train ing skill. The south matched to vermilion ,so Master Monk Yi Deng was always dressed in a piece of vermilion cassock. The south matched to the rosefinch as the holy beast. In the ancient myths, rosefinch was also known as the fire phoenix, which had lots of virtues and the legendary peculiarity of reborning from fire. Novel set the plot that the southern emperor had unique life experience and mental struggling, by which he ultimately got the insight of the world. At the meantime, he was reborn from the fire in the spirit world. Therefore, he made greater progress his martial accomplishments and personal moral cultivation, which let him reach the respected realm.

Hong Seven, nicknamed the northern beggar, dressed in beggar's dirty clothes every day, was a hermit lived just like the ordinary citizen. Because the north matched to the wood, his family name Hong was a Chinese character with water character attributes. It was said by ancient books that "The north, promoted by the tortoise snake form-fitting beast, which guarded the north, in charge of the wind and rain". Hong Seven himself and generations of disciple of beggar Gangs were all based on the northern area, committed to containing the enemy soldiers of Jin dynasty and resisting them for invading to the south. In the process of the novel in shaping Hong Seven, the author adopted the different idea. According to the praising of the northern beggar in novel, 
we can judge that the author gave the character with the north emperor's character and deeds which came from the ancient myths. At the meantime, the author gave the deeds of Gong Gong who was the patron saint of the north to other related events. The god of water named Gong Gong who was in charge of the north always had s erious contradiction with the god of fire named Zhu Rong. So there was an old saying that fire and water were incompatible. In much the same way as the old saying, the dirty clothes Gang and the clean clothes Gang which were both branches of beggar Gangs were incompatible too, so much so that the escalating infighting brought a huge crisis, which severely weakened the strength of beggar Gangs. The north matched to black, so Hong Seven was always dressed in beggar's clothes which were black and dirty. Although it was once said by novel that Hong Seven wore the dirty clothes and the clean clothes by turn cycling for a year, most of the images he presented to the reader were appearances of the dirty, even with soil in his nails. The north matched to the tortoise snake form-fitting beast as its holy beast. Legend goes that the tortoise's true feature was a sea turtle living in the north China sea. It was used to support the spirit mountain called Peng Lai as pillars. The turtle had so strong understanding ability so that it became immortal finally. On the other hand, the snake was the embodiment of wit and cleverness in people's mind.

In novel, the northern beggar was endowed with the character of chivalrousness, integrity, sharp-sight and openmind. According to the five-ele ments matching five-dragons theory, the holy beasts which matched to the five elements were the five-color dragons. Legend goes that

"Dragon born nine sons, each were not identical". The seventh son of the dragon called Bi An upheld justice and was able to distinguish between right and wrong. Similarly, Hong Seven was endowed with the character of impartiality. He once said that he had never killed a good man. In the novel, Jin Yong named the northern beggar with Hong Seven, which are not optional. Otherwise why not called him Hong Six, or Hong Nine, but just called him Hong Seven.

Wang Chongyang, nicknamed the central avatar, who was always dressed in a piece of yellow robe for Taoist priest, built the living dead tomb. He was the founder of Quanzhen Daoism, living in the Zhongnan Mountain finally. The centre matched to the soil, so those two Chinese characters Wang and Chong which came from the name both had soil character attributes. This kind of behavior that he built the living dead tomb was very adapt to the fiveelements theory in fact. According to the five-elements theory, fire could promote soil. So the southern emperor who matched to the fire taught Yiyangzhi to the central avatar who matched to the soil, and helped him to defeat the western evils in order to protect the Nine Yin Manual. The centre matched to yellow, so Wang Chongyang himself and the disciple of Quanzhen Daoism were all dressed in yellow robes for Taoist priest. The centre matched to the yellow dragon as its holy beast, which was the chief of the other four holy beasts. The yellow dragon was in the middle of the other four holy beasts, protecting the central plains.
According to the five-dragons matching five-elements theory, the yellow dragon also had taller position than the other dragons. Yellow dragon was a symbol of imperial power, also a symbol of the centre and chief, which was paramount. The central avatar Wang Chongyang was the strongest in the novel. That was reflected by his famous fighting in the first session of Huashan-Cup international martial arts tournament. Because of the fighting, Wang Chongyang became the head of the "five greats".

\section{CHARACTER CREATION AND DIVERSE ClASSICAL LITERATURE MATERIAL}

In shaping the figure respect, the legend of the Condor Heroes learned widely from others' strong points, including diverse classical literature material such as myth, historical biography, folk tales, etc. It was highlighted of this point in shaping Wang Chongyang respect.

Wang Chongyang, nicknamed the central avatar. The patron saint who was in charge of the central range is Hou $\mathrm{Tu}$, also known as the soil empress, was derived from the land worship and women worship which were both the nature worship of the matriarchal society. In Taoist legends, the soil empress stood out from the Taoist deities as the fourth emperor of heaven.She was in charge of Yin and Yang and nourished all things on earth. She was known as the mother of the earth, also the earliest king of the earth as legend said. Afterwards, she matched to the celestial emperor who was in charge of the heaven, but not get married. Gradually, she became the female god who dominated the earth, mountains and rivers. In ancient times, Hou Tu and the Yellow Emperor were both the gods of the central range. The heaven had the property of Yang and the earth had the property of Yin, and the emperor and empress were corresponding, so $\mathrm{Hou} \mathrm{Tu}$ became a female god gradually. But Jin Yong evidently had some deviation from the great god when he shaped the figure of Wang Chongyang. On the contrary, he used a more complicated delicate technique. The plot of Wang chongyang and Lin Chaoying who was the founder of the ancient tomb parties, was blended of many legends including the celestial emperor, the Yellow Emperor, Lv Dongbin, the Hou Tu empress and real version of the legend of Wang Chongyang.

In the novel, the tomb was really built by Wang Chongyang. In order to force into a marriage with Wang Chongyang, Lin Chaoying made a bet with him that Wang Chongyang should marry her or move away from the tomb if he lost the bet. At last, Lin Chaoying won the bet by cheating. Surprisingly, Wang Chongyang didn't marry her but moved away from home. The bridge was derived from Taoist legend the Hou Tu empresses cheated the founder god of Taoist. According to the legend, there was a piece of geomantic treasure land at the junction of the two counties Pinglu and Ruicheng. Originally, the land was selected by Lv Dongbin for his fane who was the founder god of Taoist. Afterwards, the Hou Tu empresses Er Huang and Nv Ying got the land for their fane by cheating. Founder god Lv took a fancy to the land at the first sight when he was fly ing in the clouds over the Zhongtiao Moutain during his aimless travel. Then he threw his sword which was immediately 
stuck in the ground as a tag. It was not expected that the Hou Tu empresses took a fancy to the land too, however it was engaged by Founder god Lv. The Hou Tu empresses were unwilling to give up, so they tried their best to strive for the land before Founder god Lv began to build his fane on it . They buried a pair of embroidered shoes in the ground, inserted Lv's sword in shoes. They cheated Founder god Lv that the land had been marked by them before him, which had the shoes in it as a tag. Founder god Lv was so aboveboard that had no thoughts of being cheated. The Hou Tu empresses put the land to their own at that.

\section{CONCLUSION}

There were many plots which used similar technique in the legend of the Condor Heroes. They gave a person with deep impression by the plots which were blended of classical literature material. Jin Yong used his deep knowledge of the literary language to analy and sort the literature material hidden in the diverse literature forms, ulteriorly turned them into his own creation material, which was used to design the architecture and to portray. The plots seemed to have met before, however left no trace. The charm and artistic value of the works was brought by traditional culture. The reader back to the original texts in his works, to find a cultural identity and spiritual habitat. At present, to inherit the classical literature naturally is very important work. Inheritance is the foundation of innovation. To understand and develop the traditional is more important than to innovate blindly.

\section{REFERENCES}

[1] Meng Qingbo, Liu Caiyan, "Three reflection on the overseas Chinese studies," Journal of social science BBS, vol.6, pp.237-241, 2013.

[2] Zhang Jing, Zhang Haitao, "Mr Ye Jiaying academic research review," Journal of literature and culture, vol.2, pp.35-43, 2014.

[3] Chen Jia, "Classical literat ure research methodology review,"Modern language (literature), vol.2, pp.147-148, 2009.

[4] Du Weiming, "The contemporary value of Chinese traditional culture," Journal of jianghai, vol.3, pp. 5-7, 2011.

[5] Wu Shaohua, "Theory of contemporary pop music creation in the classical factors,"Journal of taste, vol. 3, pp. 54-55,59, 2013.

[6] Gu Bin, Yang Qingquan, "Jin Yong and the crisis of contemporary Chinese literature,"Journal of southwest university (social science edition), vol. 20 (2) , pp.75-75, 2012. 